\title{
Galangin and Kaempferol Suppress Phorbol-12- Myristate-13-Acetate-Induced Matrix Metalloproteinase-9 Expression in Human Fibrosarcoma HT-1080 Cells
}

\author{
Yu Jung Choi, Young Hun Lee, and Seung-Taek Lee*
}

\begin{abstract}
Matrix metalloproteinase (MMP)-9 degrades type IV collagen in the basement membrane and plays crucial roles in several pathological implications, including tumorigenesis and inflammation. In this study, we analyzed the effect of flavonols on MMP-9 expression in phorbol-12-myristate-13-acetate (PMA)-induced human fibrosarcoma HT-1080 cells. Galangin and kaempferol efficiently decreased MMP-9 secretion, whereas fisetin only weakly decreased its secretion. Galangin and kaempferol did not affect cell viability at concentrations up to $30 \mu \mathrm{M}$. Luciferase reporter assays showed that galangin and kaempferol decrease transcription of MMP-9 mRNA. Moreover, galangin and kaempferol strongly reduce IKB $\alpha$ phosphorylation and significantly decrease JNK phosphorylation. These results indicate that galangin and kaempferol suppress PMA-induced MMP-9 expression by blocking activation of NF-kB and AP-1. Therefore, these flavonols could be used as chemopreventive agents to lower the risk of diseases involving MMP-9.
\end{abstract}

\section{INTRODUCTION}

Matrix metalloproteinases (MMPs) are a family of zinc-dependent endopeptidases, and there are 23 different types of human MMPs. These proteases collectively degrade structural components of the extracellular matrix (ECM). Controlled degradation of ECM proteins by MMPs is observed in many normal physiological processes, including embryogenesis, wound healing, and tissue remodeling. In contrast, uncontrolled MMP activity is implicated in pathological situations such as tumor invasion, metastasis, rheumatoid arthritis, osteoarthritis, and cardiovascular diseases (Kim et al., 2013; Visse and Nagase, 2003; Yan and Boyd, 2007).

Gelatinolytic MMPs, including MMP-2 and MMP-9, degrade type IV collagen, a major component of the basement membrane. Basement membrane degradation is involved in the initiation and

Department of Biochemistry, College of Life Science and Biotechnology, Yonsei University, Seoul 120-749, Korea

${ }^{*}$ Correspondence: stlee@yonsei.ac.kr

Received 13 August, 2014; revised 4 November, 2014; accepted 5 November, 2014; published online 10 December, 2014

Keywords: flavonol, galangin, kaempferol, mitogen-activated protein kinase, MMP-9, NF-kB progression of important diseases, including cancer, atherosclerosis, and inflammatory disorders (Coussens et al., 2002; Liotta et al., 1991; Nelson et al., 2000). MMP-9 is synergistically upregulated by growth factors and inflammatory cytokines (Bond et al. 1998). Therefore, downregulation of MMP-9 would be effective to prevent or alleviate these diseases.

Flavonoids are polyphenolic compounds that are ubiquitously found in foods of plant origin. They are known to have antioxidant and anticarcinogenic effects (Hanneken et al., 2006; Knekt et al., 2002; Scalbert et al., 2005). Flavonols are a class of flavonoids that have a 3-hydroxy flavone backbone. Their diversity comes from phenolic hydroxyl $(-\mathrm{OH})$ groups at different numbers and positions. MMP catalytic activity is regulated at several levels, including transcription, as well as activation and inhibition. We previously showed that phorbol-12-myristate-13acetate (PMA) transactivates MMP-9 expression in HCC cells in an AP-1 and NF-kB dependent manner (Hah and Lee, 2003). Herein we have evaluated modulation of PMA-induced MMP-9 expression in HT-1080 cells using eight different commercially available flavonols. In addition, we have analyzed the signaling pathways involved in flavonol-mediated MMP-9 suppression.

\section{MATERIALS AND METHODS}

\section{Chemicals}

3-hydroxyflavone (purity > 98.0\%) was obtained from Tokyo Chemical Industry (Japan). Galangin (purity $\geq 95.0 \%$ ), kaempferol (purity $\geq 90.0 \%$ ), fisetin (purity $\geq 98.0 \%$ ), quercetin (purity $\geq$ $98.0 \%$ ), morin (purity $\geq 85.0 \%$ ), and myricetin (purity $\geq 96.0 \%$ ) were obtained from Sigma-Aldrich (USA). Gossypetin (purity $\geq$ 97.0\%) was obtained from Timtec (USA). 3-(4,5-dimethylthiazol2-yl)-2,5-diphenyltetrazolium bromide (MTT) was obtained from Sigma-Aldrich. PMA was obtained from A.G. Scientific (USA). Anti-MMP-9, anti-phospho-ERK1/2, anti-ERK, anti-phospho-JNK, anti-JNK, anti-phospho-p38 MAPK, anti-phospho-IкB $\alpha$, and anti-I $\mathrm{KB} \alpha$ antibodies were purchased from Cell Signaling Technology (USA). The anti-p38 MAPK antibody was purchased from Santa Cruz Biotechnology (USA). The anti-GAPDH antibody was purchased from AbClon (Korea). Horseradish peroxidase-conjugated goat-anti mouse or rabbit $\operatorname{lgG}$ antibodies were purchased from KOMA (Korea).

\section{Cell culture}

Human fibrosarcoma HT-1080 cells were maintained in Dulbecco's modified Eagle media (DMEM) (Thermo Scientific, 
USA) supplemented with $10 \%$ fetal bovine serum (FBS), 100 $\mathrm{U} / \mathrm{ml}$ penicillin, and $100 \mu \mathrm{g} / \mathrm{ml}$ streptomycin in a humidified culture incubator at $37^{\circ} \mathrm{C}$ containing $5 \% \mathrm{CO}_{2}$. When flavonols were added to cells, they were solubilized in dimethylsulfoxide (DMSO). Cells were incubated in DMEM containing DMSO at a final concentration of less than $0.2 \%$.

\section{Gelatin zymography assays}

Subconfluent HT-1080 cells were plated in a 12-well plate and incubated for $24 \mathrm{~h}$ with serum-free media with $30 \mathrm{ng} / \mathrm{ml}$ PMA and various concentrations of flavonols. Conditioned media were subjected to gelatin zymography assays (Lv et al., 2013, Nam et al., 2011) using $7.5 \%$ SDS gels containing $0.1 \%$ gelatin Gels were incubated for $1 \mathrm{~h}$ at room temperature in refolding buffer $(50 \mathrm{mM}$ Tris- $\mathrm{HCl}, \mathrm{pH}$ 7.4, $100 \mathrm{mM} \mathrm{NaCl}, 2.5 \%$ Triton X$100)$ and for $16 \mathrm{~h}$ at $37^{\circ} \mathrm{C}$ in reaction buffer $(50 \mathrm{mM}$ Tris- $\mathrm{HCl}$, $\mathrm{pH} 7.4,10 \mathrm{mM} \mathrm{CaCl}_{2}$ ). Gels were then stained with Coomassie brilliant blue $\mathrm{R}-250$.

\section{Cell proliferation assays}

Subconfluent HT-1080 cells were plated in 96-well plates and incubated for $24 \mathrm{~h}$ in media supplemented with $10 \%$ FBS and various concentrations of galangin and kaempferol. After incubation, cells were treated with MTT solution, solubilized with DMSO, and the absorbance at $565 \mathrm{~nm}$ was measured using a microplate reader as described previously (Shin et al., 2008).

\section{Dual-luciferase reporter assays}

Subconfluent HT-1080 cells were plated in 24-well plates and co-transfected with a firefly luciferase reporter construct pGL3M9Pwt containing the human wild-type MMP-9 promoter (Hah and Lee, 2003) and a Renilla luciferase reporter vector pRL-TK. Cells were transfected using WelFect-EX plus transfection reagent (Welgene, Korea) according to the manufacturer's recommendations. After incubation for $24 \mathrm{~h}$ in complete media, the media was replaced with serum-free media and cells were then treated for $24 \mathrm{~h}$ with $30 \mathrm{ng} / \mathrm{ml} \mathrm{PMA}$ and $30 \mu \mathrm{M}$ galangin or kaempferol. Luciferase activity of the cell lysates was measured using a dual-luciferase reporter assay system (Promega, USA).

\section{Western blotting and immunodetection}

Cells were lysed using RIPA lysis buffer [50 mM Tris- $\mathrm{HCl}, \mathrm{pH}$ 7.4, $150 \mathrm{mM} \mathrm{NaCl}, 1 \% \mathrm{NP}-40,0.5 \%$ deoxycholate, $0.1 \%$ SDS, $1 \mathrm{mM} \mathrm{NaF}, 1 \mathrm{mM}$ sodium orthovanadate, protease inhibitor cocktail set I (Calbiochem, Germany)] on ice for $15 \mathrm{~min}$, followed by centrifugation for $15 \mathrm{~min}$ at $13,000 \times g$ at $4^{\circ} \mathrm{C}$. Supernatants were resuspended in SDS sample buffer $(50 \mathrm{mM}$ Tris$\mathrm{HCl}, \mathrm{pH} 6.8,2 \%$ SDS, $0.1 \%$ bromophenol blue, $10 \%$ glycerol) containing $100 \mathrm{mM} \beta$-mercaptoethanol, and resolved by SDSPAGE. Proteins were blotted onto nitrocellulose or PVDF membranes and incubated with primary and secondary antibodies. Immunoreactive signals were detected using Immobilon Western Chemiluminescent HRP Substrate (Millipore, USA) and LAS-3000 (Fujifilm, Japan).

\section{Statistical analyses}

Data are shown as the mean \pm standard deviation of at least three independent experiments. Comparisons of group means were performed using Student's $t$-tests.

\section{RESULTS}

Some flavonols decrease secretion of MMP-9

We analyzed the effect of eight different flavonols (Supplemen-
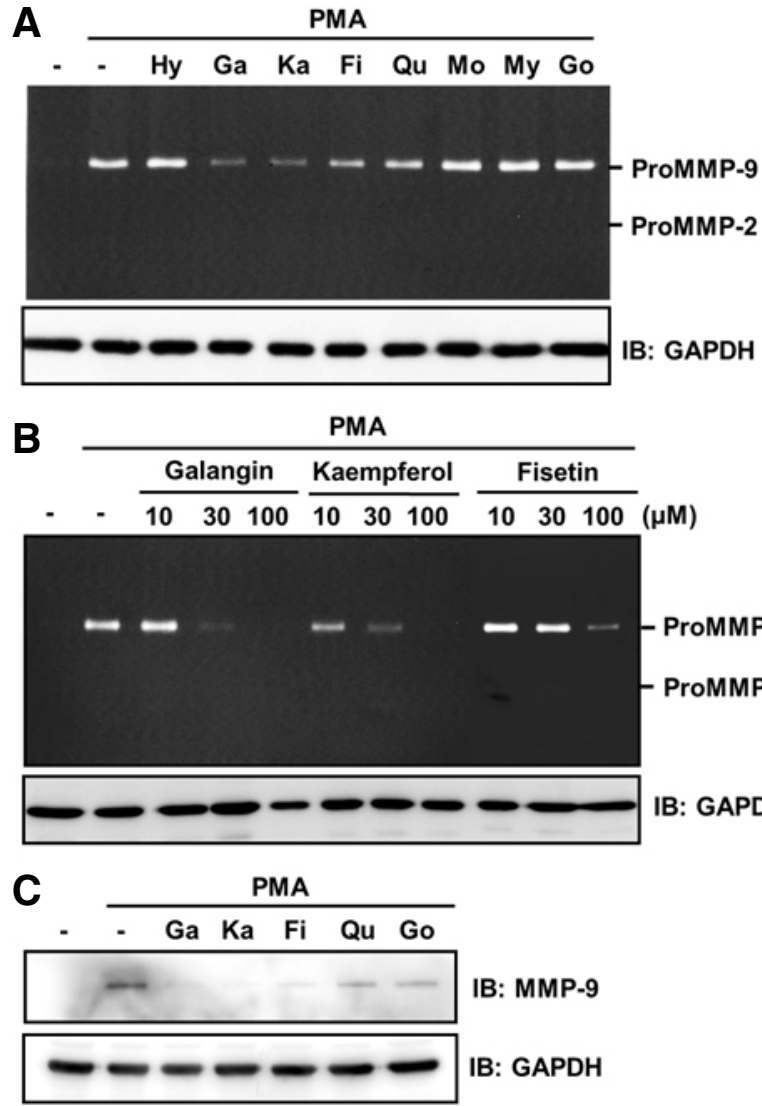

Fig. 1. Effect of flavonols on the amount of secreted MMP-9 in human fibrosarcoma HT-1080 cells. Subconfluent HT-1080 cells were incubated for $24 \mathrm{~h}$ with serum-free media in the presence of $30 \mu \mathrm{M}$ flavonols $(\mathrm{A}, \mathrm{C})$ or the indicated concentrations $(\mathrm{B})$ and 30 $\mathrm{ng} / \mathrm{ml}$ PMA. Conditioned media were subjected to gelatin zymography assays (A, B) or Western blot analysis with MMP-9 antibody (C). GAPDH immunoblots in cell lysates are shown to normalize the cell number used in this experiment. -, DMSO; Hy, 3-hydroxyflavone; $\mathrm{Ga}$, galangin; Ka, kaempferol; Fi, fisetin; Qu, quercetin; Mo, morin; My, myricetin; Go, gossypetin.

tary Fig. S1) on PMA-induced MMP-9 expression in HT-1080 cells using gelatin zymography assays. As expected, we found that PMA treatment significantly increased secretion of proMMP-9 (Fig. 1A). When each flavonol was added at a concentration of $30 \mu \mathrm{M}$, PMA-induced MMP-9 secretion was clearly reduced by galangin and kaempferol, moderately reduced by fisetin, and weakly reduced by quercetin (Fig. 1A). Dosedependent treatment of galangin, kaempferol, and fisetin showed that galangin and kaempferol reduce MMP-9 secretion more efficiently than fisetin (Fig. 1B). Western blot analysis also demonstrated that galangin, kaempferol, and fisetin decrease the PMA-induced MMP-9 secretion (Fig. 1C).

Galangin and kaempferol did not affect cell proliferation at concentrations up to $30 \mu \mathrm{M}$

To examine whether reduced MMP-9 secretion induced by galangin and kaempferol may result from their cytotoxicity, we used MTT assays to analyze the effect of galangin and kaempferol on HT-1080 cell proliferation. Cell proliferation was not affected by $30 \mu \mathrm{M}$ galangin or kaempferol and was only weakly 

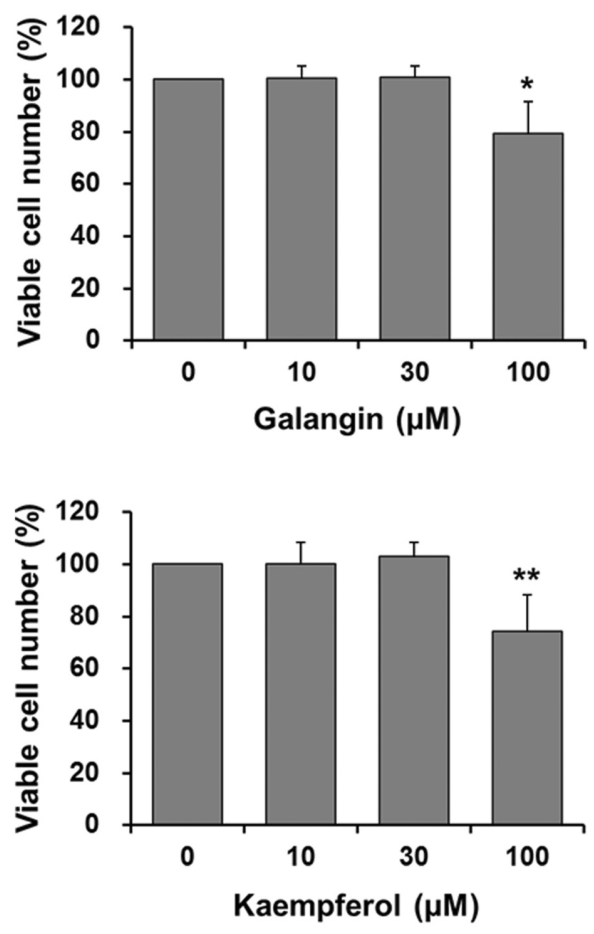

Fig. 2. Effect of galangin and kaempferol on HT-1080 cell proliferation. Cells $\left(1 \times 10^{4}\right.$ per well) were plated in 96 -well plates. Subconfluent cells were incubated for $24 \mathrm{~h}$ with various concentrations of galangin or kaempferol. The number of viable cells was determined by measuring absorbance at a wavelength of $565 \mathrm{~nm}$ after incubating cells with $\mathrm{MTT}$ reagent. The relative viable cell number (\%) in the presence of flavonols is expressed relative to the cell number in the absence of flavonols. Each value is the mean \pm standard deviation from at least three independent determinations. ${ }^{*} p<0.05$; ${ }^{* *} p<$ 0.01 vs. no flavonol.

inhibited by $100 \mu \mathrm{M}$ galangin (79.4\%) and kaempferol (74.3\%) (Fig. 2). Thus, $30 \mu \mathrm{M}$ galangin or kaempferol did not affect cell viability and was selected as the concentration for the following experiments.

Galangin and kaempferol inhibit MMP-9 gene transcription To analyze whether galangin- and kaempferol-mediated inhibition of MMP-9 secretion is due to suppression of MMP-9 transcription, we performed promoter assays using cells transiently transfected with a luciferase reporter gene linked to the MMP-9 promoter sequence (pGL3-M9Pwt). Luciferase activity driven by the MMP-9 promoter increased up to 22 -fold in cells treated with PMA compared to untreated cells (Fig. 3). The addition of galangin or kaempferol $(30 \mu \mathrm{M})$ to cells decreased luciferase activity to approximately $40 \%$ of control. This result demonstrates that galangin and kaempferol suppress PMA-induced transcription of the MMP-9 gene.

Galangin and kaempferol abrogate PMA-induced MMP-9 expression by blocking the NF-кB and AP-1 pathways MMP-9 gene transcription is activated predominantly by the mitogen-activated protein kinases (MAPKs) and NF-kB pathways (Gum et al., 1997; Sato and Seiki, 1993; Sato et al., 1993). We first investigated whether galangin and kaempferol modulate MAPK signaling pathways. To determine the optimal

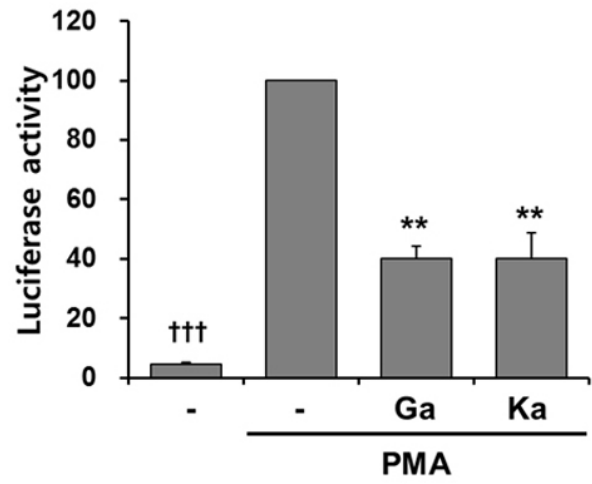

Fig. 3. Effect of galangin and kaempferol on MMP-9 transcription. HT-1080 cells were transiently co-transfected with pGL3-M9Pwt luciferase reporter constructs and pRL-TK. Cells were treated for 24 $\mathrm{h}$ with galangin and kaempferol $(30 \mu \mathrm{M})$ and PMA (30 ng/ml). Luciferase activity was measured using a dual-luciferase reporter assay system. Luciferase activity was normalized to Renilla luciferase activity. Each value is the mean \pm standard deviation from three independent determinations. ${ }^{++\dagger} p<0.001 ;{ }^{* \star} p<0.01 \mathrm{vs}$. PMA alone. -, DMSO; Ga, galangin; Ka, kaempferol.

time point for PMA-induced activation of MAPKs, HT-1080 cells were stimulated with PMA for various time intervals. PMA induced phosphorylation of MAPKs, with maximal activation of ERKs and JNK after 30-60 min and activation of p38 MAPK after 10-30 min (Fig. 4A). Pre-incubation of cells with galangin or kaempferol does not affect PMA-induced ERK1/2 and p38 MAPK phosphorylation, similar to gossypetin treatment that does not induce MMP-9 secretion. However, galangin and kaempferol significantly decreased PMA-induced JNK phosphorylation (Fig. 4B).

Next, we investigated whether galangin and kaempferol control the NF- $\mathrm{KB}$ signaling pathway. As expected, PMA treatment transiently increased $1 \kappa B \alpha$ phosphorylation and decreased $\mathrm{I}_{\mathrm{KB} \alpha} \alpha$ levels in HT-1080 cells (Fig. 5A). Interestingly, galangin and kaempferol significantly decreased $I_{\kappa} B \alpha$ phosphorylation with a concomitant increase in $1 \kappa \mathrm{B} \alpha$ levels (Fig. 5B). Taken together, these results suggest that galangin and kaempferol reduce PMA-induced MMP-9 expression by hampering NF- $\mathrm{KB}$ activation and, to a lesser extent, by inhibiting JNK activation and thereby decreasing AP-1 activation.

\section{DISCUSSION}

Some flavonols have been reported to control the function of specific MMPs by inhibiting their catalytic activity (Phromnoi et al., 2009; Sartor et al., 2002). Recently, we also found that one flavonol, fisetin, inhibits the catalytic activity of various MMPs, including MMP-14, and reduces MMP-dependent cellular processes, such as tumor cell invasion and endothelial cell tube formation (Park et al., 2013). In addition MMP inhibition, it has recently been shown that flavonols can regulate MMP function through transcriptional suppression. For example, kaempferol suppresses PMA-induced MMP-9 expression in glioblastoma GBM8401 cells (Lin et al., 2010), MMP-2 expression in tongue squamous cell carcinoma SCC4 cells (Lin et al., 2013), and MMP-2 and MMP-9 expression in human osteosarcoma U-2 OS cells (Chen et al., 2013). Quercetin downregulates oxidized LDL-induced expression of MMP-1, MMP-2, and MMP-9 in human umbilical vein endothelial EA.hy926 cells ( $\mathrm{Yi}$ et al., 
Suppression of MMP-9 by Galangin and Kampferol Yu Jung Choi et al.

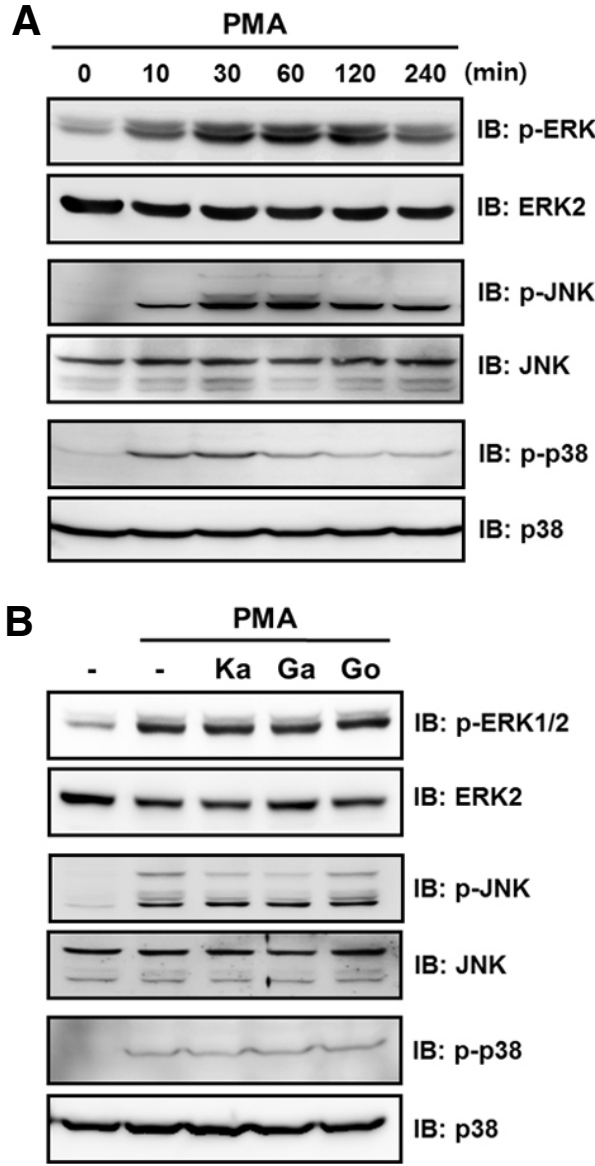

Fig. 4. Effect of galangin and kaempferol on PMA-induced activation of MAPKs. (A) To determine the optimal time point for PMAinduced activation of MAPKs, cells were starved for $24 \mathrm{~h}$ and then stimulated with $30 \mathrm{ng} / \mathrm{ml}$ PMA for the indicated time intervals. (B) Cells were starved for $24 \mathrm{~h}$, preincubated for $30 \mathrm{~min}$ with $30 \mu \mathrm{M}$ of galangin, kaempferol, or gossypetin (as a negative control), and stimulated for $30 \mathrm{~min}$ with $30 \mathrm{ng} / \mathrm{ml}$ PMA. Cell lysates were subjected to $10 \%$ SDS-PAGE and analyzed by Western blotting. ERK, JNK, and p38 MAPK levels in cell lysates were analyzed as loading controls. Ka, kaempferol; Ga, galangin; Go, gossypetin.

2012), decreases phenazine methosulfate-induced expression and activation of MMP-2, as well as decreases MMP-9 expression in HT-1080 cells (Lee et al., 2013). Morin decreases MMP2 and MMP-9 expression during diethylnitrosamine-induced hepatocellular carcinoma in rats (Sivaramakrishnan and Niranjali Devaraj, 2009). However, the effect of diverse flavonols on MMP-9 expression in a cellular system has not yet been evaluated.

Here we investigated the effect of eight commercially available flavonols on PMA-induced MMP-9 secretion in HT-1080 cells using gelatin zymography assays. Although suppression of MMP-9 expression by kaempferol, quercetin, and morin was reported in different conditions (Chen et al., 2013; Lee et al., 2013; Lin et al., 2010; 2013; Sivaramakrishnan and Niranjali Devaraj, 2009; Yi et al., 2012), our study showed that MMP-9 secretion from HT-1080 cells was severely decreased by galangin as well as kaempferol, and moderately decreased by fisetin. Interestingly, quercetin weakly affected and morin did
A PMA

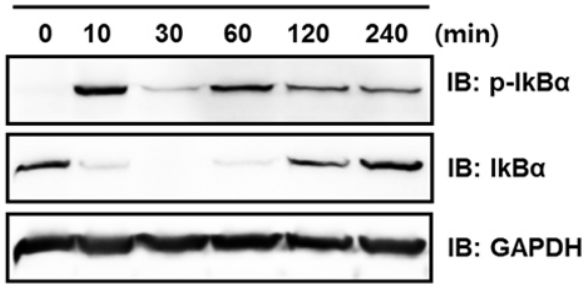

B

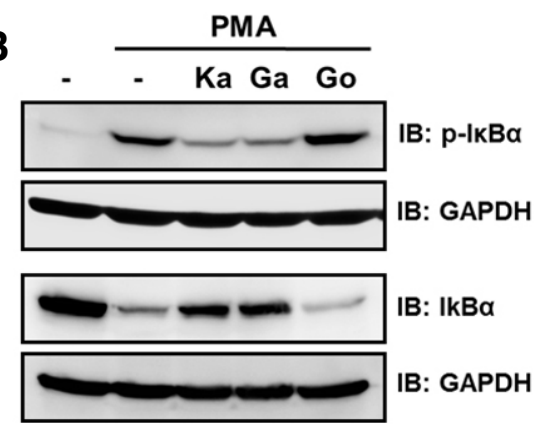

Fig. 5. Effect of galangin and kaempferol on PMA-induced activation of NF-kB. (A) Cells were starved for $24 \mathrm{~h}$ and then stimulated with $30 \mathrm{ng} / \mathrm{ml}$ PMA for the indicated time intervals. (B) Cells were starved for $24 \mathrm{~h}$, preincubated for $30 \mathrm{~min}$ with $30 \mu \mathrm{M}$ of galangin, kaempferol, or gossypetin (as a negative control), and stimulated for $10 \mathrm{~min}$ with $30 \mathrm{ng} / \mathrm{ml}$ PMA. Cell lysates were subjected to $10 \%$ SDS-PAGE and analyzed by Western blotting. GAPDH level in cell lysates were analyzed as loading controls. Ka, kaempferol; Ga, galangin; Go, gossypetin.

not affect MMP-9 secretion. Because galangin and kaempferol did not affect cell proliferation at concentrations up to $30 \mu \mathrm{M}$, the reduced MMP-9 secretion by galangin and kaempferol could not be attributed to their cytotoxicity.

As expected, we found that the galangin- and kaempferolmediated decrease in MMP-9 secretion results from suppression of MMP-9 mRNA transcription. It is known that AP-1 and NF- $\mathrm{kB}$ transcription factors are important for MMP-9 induction by growth factors, cytokines, and PMA in various cell types (Lee et al., 2014; Lianxu et al., 2006; Shin et al., 2002). We found that galangin and kaempferol drastically decrease $I_{\kappa} \mathrm{B} \alpha$ phosphorylation and increase $I_{\kappa} \mathrm{B} \alpha$ levels. In addition, galangin and kaempferol significantly reduce JNK phosphorylation and thus are expected to decrease AP-1 activation. However, neither flavonol changes phosphorylation of other MAPKs. These results demonstrate that galangin and kaempferol suppress PMA-induced MMP-9 transactivation by inhibiting both the NF$\kappa \mathrm{B}$ and $\mathrm{AP}-1$ pathways.

In conclusion, this is the first comparative study regarding the effect of various flavonols on MMP-9 suppression. We found that galangin is able to downregulate MMP-9 expression as efficiently as kaempferol, which is a well-known MMP-9 suppressor in various cell types (Chen et al., 2013; Lin et al., 2010). We also demonstrated that galangin and kaempferol suppress MMP-9 transcription by inhibiting both the NF- $\mathrm{KB}$ and AP-1 pathways. The identification of galangin and kaempferol as suppressors of MMP-9 expression is meaningful because they are natural components present in a wide variety of fruits, vegetables and plants (e.g., ginger, broccoli, tomato, strawberry, and apple). In particular, enhanced MMP-9 expression is associated 
with several pathologies, such as tumor invasion and metastasis as well as inflammation (Watanabe et al., 1993; Zheng et al., 2006). Therefore, galangin and kaempferol might be used as chemopreventive compounds to control inflammation and malignant diseases.

Note: Supplementary information is available on the Molecules and Cells website (www.molcells.org).

\section{ACKNOWLEDGMENTS}

This work was supported by grants from the National Research Foundation of Korea funded by the Ministry of Education (2013R1A2A2A01013884) and the Ministry of Science, ICT \& Future Planning (2014M3C9A2064536). Y.J.C. and Y.H.L. were graduate student trainees of the Brain Korea 21 plus program from the Ministry of Education, Republic of Korea.

\section{REFERENCES}

Bond, M., Fabunmi, R.P., Baker, A.H., and Newby, A.C. (1998). Synergistic upregulation of metalloproteinase- 9 by growth factors and inflammatory cytokines: an absolute requirement for transcription factor NF-kappa B. FEBS Lett. 435, 29-34.

Chen, H.J., Lin, C.M., Lee, C.Y., Shih, N.C., Peng, S.F., Tsuzuki, M., Amagaya, S., Huang, W.W., and Yang, J.S. (2013). Kaempferol suppresses cell metastasis via inhibition of the ERK-p38-JNK and AP-1 signaling pathways in U-2 OS human osteosarcoma cells. Oncol. Rep. 30, 925-932.

Coussens, L.M., Fingleton, B., and Matrisian, L.M. (2002). Matrix metalloproteinase inhibitors and cancer: trials and tribulations. Science 295, 2387-2392.

Gum, R., Wang, H., Lengyel, E., Juarez, J., and Boyd, D. (1997). Regulation of $92 \mathrm{kDa}$ type IV collagenase expression by the jun aminoterminal kinase- and the extracellular signal-regulated kinase-dependent signaling cascades. Oncogene 14, 14811493.

Hah, N., and Lee, S.T. (2003). An absolute role of the PKCdependent NF-kappaB activation for induction of MMP-9 in hepatocellular carcinoma cells. Biochem. Biophys. Res. Commun. 305, 428-433.

Hanneken, A., Lin, F.F., Johnson, J., and Maher, P. (2006). Flavonoids protect human retinal pigment epithelial cells from oxidative-stress-induced death. Invest. Ophthalmol. Vis. Sci. 47, 3164-3177.

Kim, H.I., Saldova, R., Park, J.H., Lee, Y.H., Harvey, D.J., Wormald, M.R., Wynne, K., Elia, G., Kim, H.-J., Rudd, P.M., and Lee, S.-T. (2013) The presence of outer arm fucose residues on the $N$ glycans of tissue inhibitor of metalloproteinases-1 reduces its activity. J. Proteome Res. 12, 3547-3560.

Knekt, P., Kumpulainen, J., Jarvinen, R., Rissanen, H., Heliovaara, M., Reunanen, A., Hakulinen, T., and Aromaa, A. (2002). Flavonoid intake and risk of chronic diseases. Am. J. Clin. Nutr. 76, 560-568.

Lee, D.E., Chung, M.Y., Lim, T.G., Huh, W.B., Lee, H.J., and Lee, K.W. (2013). Quercetin suppresses intracellular ROS formation, MMP activation, and cell motility in human fibrosarcoma cells. J. Food Sci. 78, H1464-1469.

Lee, S.U., Ahn, K.S., Sung M.H., Park, J.W., Ryu, H.W., Lee, H.J., Hong, S.T., and Oh, S.R. (2014). Indacaterol inhibits tumor cell invasiveness and MMP-9 expression by suppressing IKK/NF-kB activation. Mol. Cells 37, 585-591.

Lianxu, C., Hongti, J., and Changlong, Y. (2006). NF-kappaBp65specific siRNA inhibits expression of genes of COX-2, NOS-2 and MMP-9 in rat IL-1beta-induced and TNF-alpha-induced chondrocytes. Osteoarthritis Cartilage 14, 367-376.

Lin, C.W., Shen, S.C., Chien, C.C., Yang, L.Y., Shia, L.T., and Chen, Y.C. (2010). 12-O-tetradecanoylphorbol-13-acetate-induced invasion migration of glioblastoma cells through activating PKCalpha/ ERK/NF-kappaB-dependent MMP-9 expression. J. Cell Physiol. 225, 472-481.

Lin, C.W., Chen, P.N., Chen, M.K., Yang, W.E., Tang, C.H., Yang, S.F., and Hsieh, Y.S. (2013). Kaempferol reduces matrix metalloproteinase-2 expression by down-regulating ERK1/2 and the activator protein-1 signaling pathways in oral cancer cells. PLoS One 8, e80883.

Liotta, L.A., Steeg, P.S., and Stetler-Stevenson, W.G. (1991). Cancer metastasis and angiogenesis: an imbalance of positive and negative regulation. Cell 64, 327-336.

Lv, Z., Yang, D., Li, J., Hu, M., Luo, M., Zhan, X., Song, P., Liu, C., Bai, H., Li, B., et al. (2013). Bone morphogenetic protein 9 overexpression reduces osteosarcoma cell migration and invasion. Mol. Cells 36, 119-126

Nam, Y.H., Ryu, E., Lee,D., Shim, H.J., Lee, Y.C., and Lee, S.T. (2011). CagA phosphorylation-dependent MMP-9 expression in gastric epithelial cells. Helicobacter 16, 276-283.

Nelson, A.R., Fingleton, B., Rothenberg, M.L., and Matrisian, L.M. (2000). Matrix metalloproteinases: biologic activity and clinical implications. J. Clin. Oncol. 18, 1135-1149.

Park, J.H., Jang, Y.J., Choi, Y.J., Jang, J.W., Kim, J.H., Rho, Y.K., Kim, I.J., Kim, H.J., Leem, M.J., and Lee, S.T. (2013). Fisetin inhibits matrix metalloproteinases and reduces tumor cell invasiveness and endothelial cell tube formation. Nutr. Cancer 65, 1192-1199.

Phromnoi, K., Yodkeeree, S., Anuchapreeda, S., and Limtrakul, P. (2009). Inhibition of MMP-3 activity and invasion of the MDAMB-231 human invasive breast carcinoma cell line by bioflavonoids. Acta Pharmacol. Sin. 30, 1169-1176.

Sartor, L., Pezzato, E., Dell'Aica, I., Caniato, R., Biggin, S., and Garbisa, S. (2002). Inhibition of matrix-proteases by polyphenols: chemical insights for anti-inflammatory and anti-invasion drug design. Biochem. Pharmacol. 64, 229-237.

Sato, H., and Seiki, M. (1993). Regulatory mechanism of $92 \mathrm{kDa}$ type IV collagenase gene expression which is associated with invasiveness of tumor cells. Oncogene 8, 395-405.

Sato, H., Kita, M., and Seiki, M. (1993). v-Src activates the expression of 92-kDa type IV collagenase gene through the AP1 site and the GT box homologous to retinoblastoma control elements. A mechanism regulating gene expression independent of that by inflammatory cytokines. J. Biol. Chem. 268, 23460-23468.

Scalbert, A., Manach, C., Morand, C., Remesy, C., and Jimenez, L. (2005). Dietary polyphenols and the prevention of diseases. Crit. Rev. Food Sci. Nutr. 45, 287-306.

Shin, M., Yan, C., and Boyd, D. (2002). An inhibitor of c-jun aminoterminal kinase (SP600125) represses c-Jun activation, DNAbinding and PMA-inducible 92-kDa type IV collagenase expression. Biochim. Biophys. Acta 1589, 311-316.

Shin, W.S., Maeng, Y.S., Jung, J.W., Min, J.K., Kwon, Y.G., and Lee, S.T. (2008). Soluble PTK7 inhibits tube formation, migration, and invasion of endothelial cells and angiogenesis. Biochem. Biophys. Res. Commun. 371, 793-798.

Sivaramakrishnan, V., and Niranjali Devaraj, S. (2009). Morin regulates the expression of NF-kappaB-p65, COX-2 and matrix metalloproteinases in diethylnitrosamine induced rat hepatocellular carcinoma. Chem. Biol. Interact 180, 353-359.

Visse, R., and Nagase, H. (2003). Matrix metalloproteinases and tissue inhibitors of metalloproteinases: structure, function, and biochemistry. Circ. Res. 92, 827-839.

Watanabe, H., Nakanishi, I., Yamashita, K., Hayakawa, T., and Okada, Y. (1993). Matrix metalloproteinase-9 (92 kDa gelatinase/type IV collagenase) from U937 monoblastoid cells: correlation with cellular invasion. J. Cell Sci. 104 (Pt 4), 991-999.

Yan, C., and Boyd, D.D. (2007). Regulation of matrix metalloproteinase gene expression. J. Cell Physiol. 211, 19-26.

Yi, L., Chen, C.Y., Jin, X., Zhang, T., Zhou, Y., Zhang, Q.Y., Zhu, J.D., and Mi, M.T. (2012). Differential suppression of intracellular reactive oxygen species-mediated signaling pathway in vascular endothelial cells by several subclasses of flavonoids. Biochimie 94, 2035-2044.

Zheng, H., Takahashi, H., Murai, Y., Cui, Z., Nomoto, K., Niwa, H., Tsuneyama, K., and Takano, Y. (2006). Expressions of MMP-2, MMP-9 and VEGF are closely linked to growth, invasion, metastasis and angiogenesis of gastric carcinoma. Anticancer Res. 26, 3579-3583. 